\title{
TERAPI MUSIK DAN TINGKAT KECEMASAN PASIEN PREOPERASI
}

\author{
Wenny Savitri ${ }^{1}$, Nani Fidayanti ${ }^{1}$, Paulus Subiyanto ${ }^{2}$
}

\begin{abstract}
${ }^{1}$ Program Studi IImu Keperawatan, Stikes Jenderal A. Yani Yogyakarta
Jl. Ringroad Barat, Ambarketawang, Gamping, Sleman, D.I.Yogyakarta

E-mail: wenny_savitri2007@yahoo.com

${ }^{2}$ Akademi Keperawatan Panti Rapih
\end{abstract}

\begin{abstract}
Background: Surgery is one of medical interventions which can cause fear, anxiety, and stressed because of its effects toward the integrity of body and soul. Nurses have significant roles in any preoperative care which is helping patients to decrease preoperative anxiety by using complementary therapy. The use of music therapy as one of the complementary therapies is not common in Indonesia. Therefore, scientific studies to prove the role of this therapy to decrease the level of anxiety of pre-operative patients is needed.

Objective: To investigate the effects of music therapy in reducing anxiety levels of preoperative patients.

Methods: A quasy experimental study with pre-test and post-test design with control group was applied to 50 respondents from medical ward in Panembahan Senopati Hospital of Yogyakarta who met the inclusion criteria.Dara were then analyzed by using t-test statistical analysis.

Results: The control group showed the increased value of anxiety level of 0.8 without music intervention ( $\mathrm{t}=$ $1503, \mathrm{df}=24, \mathrm{p}<.05)$, whereas the intervention group showed the decreased value of anxiety level of -5.52 $(\mathrm{t}=5.081, \mathrm{df}=24, \mathrm{p}<.05)$. Meanwhile the independent $\mathrm{t}$-test results for both groups showed a significant difference between group $(t=3,373, d f=48, p<.05)$.

Conclusion: Music therapy has significant effect in reducing preoperative anxiety levels of patients.
\end{abstract}

Keywords: anxiety, preoperative, music therapy

\section{PENDAHULUAN}

Tindakan operasi baik elektif maupun kedaruratan adalah peristiwa atau kejadian kompleks yang menegangkan hampir untuk semua pasien. ${ }^{1}$ Tahapan-tahapan pada operasi harus dilakukan dengan baik dan benar, terutama pada fase preoperasi karena tahap ini merupakan tahapan awal keperawatan perioperatif. Kesalahan di tahap ini akan berakibat fatal pada tahap berikutnya. $^{2}$ Kecemasan merupakan gejala yang paling sering muncul pada tahap preoperasi. $3,4,5,6$

Kecemasan yang tidak ditangani dengan baik dapat menimbulkan adanya perubahan secara fisik maupun psikologis yang akhirnya dapat meningkatkan kerja saraf simpatis dan akan terjadi peningkatan denyut jantung, frekuensi napas, tekanan darah, keringat dingin, merasa mulas, gangguan perkemihan, dan secara umum mengurangi tingkat energi pada pasien sehingga merugikan pasien itu sendiri. ${ }^{2}$ Untuk menurunkan efek dari penggunaan obatobatan dalam mengatasi kecemasan diperlukan terapi komplementer atau terapi pelengkap yang dapat menangani tingkat kecemasan. Terapi komplementer merupakan terapi holistis atau terapi nonbiomedis. ${ }^{7} \quad$ Salah satu dari terapi komplementer yang sedang banyak dikembangkan di bidang kesehatan saat ini adalah terapi musik. Studi ini bertujuan untuk mengidentifikasi pengaruh dari terapi musik 
dalam menurunkan tingkat kecemasan pasien preoperasi.

\section{BAHAN DAN CARA PENELITIAN}

Studi ini merupakan penelitian eksperimen semu dengan menggunakan desain Pre-test and Post-test design dengan kelompok kontrol. Penelitian dilakukan di Bangsal Bedah Ruang Melati Panembahan Senopati Bantul Yogyakarta pada bulan Juni 2014. Populasi dalam penelitian ini yaitu pasien yang akan menjalani operasi bedah mayor yang pertama kali yang mengalami kecemasan. Pengambilan sampel dilakukan dengan teknik sampling Purposive sampling dengan jumlah sampel sebanyak 50 Responden.

Peneliti memberikan terapi musik menggunakan alat bantu audio dengan jenis musik yaitu: musik klasik, new age, dan chilled pop.Tingkat kecemasan diukur menggunakan Hamilton Anxiety Rating Scale (HARS). Data yang telah terkumpul, diolah dengan menggunakan analisis distribusi frekuensi dan statistic $t$-test melalui dua jenis analisis data yaitu analisis univariat dan analisis bivariat.

\section{HASIL DAN PEMBAHASAN}

Berdasarkan hasil penelitian didapat hasil bahwa karakteristik umur responden sebagian besar adalah remaja, berjenis kelamin perempuan, dengan jenjang pendidikan terakhir adalah pendidikan dasar, dengan rincian sebagai berikut:
Tabel1. Distribusi frekuensi karakteristik responden $(\mathrm{N}=50)$

\begin{tabular}{|c|c|c|c|c|}
\hline \multirow[t]{2}{*}{ Karakteristik } & \multicolumn{2}{|c|}{$\begin{array}{l}\text { Kelompok } \\
\text { kontrol }\end{array}$} & \multicolumn{2}{|c|}{$\begin{array}{l}\text { Kelomok } \\
\text { intervensi }\end{array}$} \\
\hline & $f$ & $\%$ & $f$ & $\%$ \\
\hline \multicolumn{5}{|l|}{ Umur } \\
\hline 12 - 25 tahun & 10 & 40,0 & 11 & 44,0 \\
\hline 26 - 45 tahun & 7 & 28,0 & 7 & 28,0 \\
\hline 46 - 65 tahun & 5 & 20,0 & 5 & 20,0 \\
\hline tahun & 3 & 12,0 & 2 & 8,0 \\
\hline Total & 25 & 100 & 25 & 100 \\
\hline \multicolumn{5}{|l|}{ Jenis Kelamin } \\
\hline Laki-Laki & 11 & 44,0 & 12 & 48,0 \\
\hline Perempuan & 14 & 56,0 & 13 & 52,0 \\
\hline Total & 25 & 100 & 25 & 100 \\
\hline \multicolumn{5}{|l|}{ Pendidikan } \\
\hline Pendidikan Dasar & 18 & 72,0 & 15 & 60,0 \\
\hline $\begin{array}{l}\text { Pendidikan } \\
\qquad \text { Menengah }\end{array}$ & 7 & 28,0 & 9 & 36,0 \\
\hline Perguruan Tinggi & 0 & 0 & 1 & 4,0 \\
\hline Total & 25 & 100 & 25 & 100 \\
\hline
\end{tabular}

Sumber : Data Primer 2014.

Tabel 2. Hasil uji Paired sample t-test tingkat kecemasan pre-test dan post-test pada kelompok kontrol $(\mathrm{N}=25)$

\begin{tabular}{lllccc}
\hline Variabel & $\bar{x}$ & $\mathrm{n}$ & $\mathrm{t}$ & $\mathrm{Df}$ & $P$ \\
\hline $\begin{array}{l}\text { Pre-test } \\
\text { Kontrol }\end{array}$ & 20,84 & 25 & $-1,503$ & 24 & 0,000 \\
Post-test & 21,64 & & & & \\
Kontrol & 21,64 & & & & \\
\hline
\end{tabular}

Sumber: Data Primer 2014

Tabel 2 menunjukkan bahwa hasil perhitungan statistik menggunakan paired sample t-test pada kelompok kontrol ada peningkatan tingkat kecemasan yang bermakna secara statistik pada responden kelompok kontrol $(t=-1,503 \mathrm{df}=24, \mathrm{p}<0,05)$.

Hasil uji statistik menunjukkan bahwa menggunakan paired sample t-test pada kelompok intervensi ada penurunan tingkat kecemasan yang bermakna secara statistik pada responden kelompok intervensi $(t=5,08$, $d f=24, p<0,05)$. 
Tabel 3. Hasil uji Paired sample t-test tingkat kecemasan pre-test dan post-test pada kelompok Intervensi $(\mathbf{n}=25)$

\begin{tabular}{lrrrrr}
\hline Variabel & $\bar{x}$ & $\mathrm{n}$ & $\mathrm{t}$ & $\mathrm{df}$ & $\mathrm{p}$ \\
\hline $\begin{array}{l}\text { Pre-test } \\
\text { Intervensi }\end{array}$ & 21,44 & 25 & 5,081 & 24 & 0,000 \\
\hline $\begin{array}{l}\text { Post-test } \\
\text { Intervensi }\end{array}$ & 15,92 & & & & \\
\hline
\end{tabular}

\begin{tabular}{|c|c|c|c|c|c|}
\hline \multirow{2}{*}{ Kategori } & \multirow{2}{*}{$\mathrm{N}$} & \multirow{2}{*}{$\bar{x}$} & \multirow{2}{*}{$\begin{array}{c}\text { Std.De } \\
\mathrm{v}\end{array}$} & \multicolumn{2}{|c|}{ t-test } \\
\hline & & & & $t$ & $P$ \\
\hline \multirow{4}{*}{$\begin{array}{l}\text { Kontrol } \\
\text { Intervens } \\
\mathrm{i}\end{array}$} & 2 & 21,6 & 11,833 & 3,37 & 0,00 \\
\hline & 5 & 4 & & 3 & 2 \\
\hline & 2 & 15,9 & & & \\
\hline & 5 & 2 & & & \\
\hline
\end{tabular}

Tabel 4 menunjukkan hasil perhitungan statistik menggunakan uji Independent Sample t-test diperoleh $p<0.05$ artinya ada pengaruh terapi musik terhadap tingkat kecemasan pasien preoperasi di Bangsal Bedah Ruang Melati Panembahan Senopati Bantul Yogyakarta.

Pengaruh pemberian terapi musik terhadap tingkat kecemasan pasien preoperasi di Bangsal Bedah Ruang Melati RSUD Panembahan Senopati Bantul didapat hasil analisis statistik dengan independent sample t-test menunujukkan bahwa adanya perbedaan yang signifikan terhadap tingkat kecemasan pasien preoperasi $(t=3,373$, $d f=48, p<0,05)$. Dengan demikian peneliti membuktikan bahwa adanya penurunan tingkat kecemasan pada kelompok intervensi setelah diberikan terapi musik. Terapi musik yang berupa suara diterima oleh saraf pendengaran, diubah menjadi vibrasi yang kemudian disalurkan ke otak melalui sistem limbik. Dalam sistem limbik (Amigala dan hipotalamus) memberikan stimulus ke sistem saraf atonom yang berkaitan erat dengan sistem endrokrin yang dapat menurunkan hormon-hormon yang berhubungan dengan stres dan kecemasan, kemudian stimulus mengaktifkan hormon endorphin untuk membantu meningkatkan rasa rilkes dalam tubuh seseorang. ${ }^{8}$ Sistem saraf otonom terbagi menjadi dua yaitu: sistem saraf simpatik dan parasimpatik. Kedua saraf ini memiliki fungsi yang berbeda dan bertentangan. Sistem saraf simpatik akan lebih aktif dalam menghadapi situasi yang dapat mengancam diri. Sedangkan sistem parasimpatik akan berkerja lebih aktif dalam keadaan yang normal. Seseorang dalam keadaan cemas maka sistem saraf simpatik akan meningkatkan kerja detak jantung, tekanan darah, dan pernafasan. Sebaliknya ketika seseorang dalam keadaan santai, berbaring, nafas menjadi pelan teratur maka sistem parasimpatik yang berkerja lebih aktif. ${ }^{9}$ Dalam terapi ini musik adalah fasilitator untuk membuat keadaan seseorang menjadi rileks dan nyaman sehingga kerja sistem saraf parasimpatik akan berkerja lebih dominan. Hasil penelitian ini juga didukung dari hasil penelitian sebelumnya, bahwa terapi musik dapat menurunkan tingkat kecemasan pasien yang akan menjalani operasi. ${ }^{4,5,10,11}$

Kecemasan yang terjadi pada pasien preoperasi dipengaruhi beberapa faktor yaitu 
faktor internal meliputi: umur, jenis kelamin, status pendidikan dan ekonomi, keadaan fisik, dan tipe kepribadian. Sedangkan dari faktor eksternal yaitu potensial stresor, sosial budaya, dan dukungan dari keluarga. ${ }^{12}$ Penelitian ini menunjukkan bahwa umur responden terbanyak pada kelompok kontrol dan intervensi antara 12-25 remaja. Seseorang dengan umur remaja atau masih muda lebih cendrung mengalami cemas dibandingkan dengan tingkat umur yang semakin dewasa dan lebih tua. semakin meningkatnya umur seseorang maka frekuensi kecemasan seseorang makin berkurang saat menjalani operasi. ${ }^{13}$ Faktor internal lainnya yaitu jenis kelamin. Dalam hasil penelitian didapat bahwa sebagian besar responden yang mengalami kecemasan adalah perempuan. Tingkat kecemasan pada perempuan lebih tinggi dari pada tingkat kecemasan yang dialami lakilaki. ${ }^{14}$ Perempuan lebih cendrung emosional, mudah meluapkan perasaannya, sementara laki-laki bersifat objektif dan dapat berpikir rasional sehingga mampu berpikir dan dapat mengendalikan emosi. ${ }^{11} \mathrm{Kecemasan}$ lebih sering dialami perempuan daripada laki-laki, karena perempuan sering kali menggunakan perasaan untuk menyikapi dan menghadapi sesuatu dalam hidupnya sedang laki-laki selalu menggunakan pikiran dalam menghadapi situasi yang akan mengancam dirinya. ${ }^{15}$ Sedangkan faktor pendidikan dalam hasil penelitian didapat bahwa sebagian besar responden yang mengalami kecemasan dengan tingkat pendidikan dasar. Status pendidikan yang rendah rentan sekali mengalami kecemasan dibandingan dengan pendidikan yang tinggi. Semakin tinggi tingkat pendidikan seseorang maka dapat berpikir secara rasional dan dapat mengatasi emosi dengan baik sehingga kecemasan yang dialami seseorang akan berkurang. ${ }^{16}$ Hasil uji statistik menunjukkan bahwa pada kelompok kontrol didapatkan nilai rata-rata pre-test 20,84 dan post-test 21,64 dengan nilai $(t=-1,503, d f=24 \quad p<0,05)$ berarti ada perbedaan yang signifikan terhadap tingkat kecemasan pasien preoperasi pada kelompok kontrol. Hal ini terjadi karena adanya faktor-faktor yang memengaruhi terjadinya kecemasan seperti kurangnya dukungan keluarga akan mengakibatkan seseorang mengalami kecemasan. Pada saat peneliti melakukan penelitian ada responden yang ditunggu oleh keluarganya tetapi ada juga responden yang tidak ditunggui oleh anggota keluarganya. Faktor lainnya yang dapat menyebabkan terjadinya kecemasan yaitu tipe kepribadian, orang dengan tipe kepribadian $\mathrm{A}$ akan lebih mudah mengalami kecemasan di bandingkan dengan orang tipe kepribadian B. ${ }^{12}$ Sedangkan pada kelompok intervensi berdasarkan hasil uji paired sample t-test didapat rata-rata pre-test 21,44 menjadi posttest 15,92( $\mathrm{t}=5,081, \mathrm{df}=24, \mathrm{p}<0,05)$ berarti ada perbedaan signifikan terhadap penurunan tingkat kecemasan pasien preoperasi. Penurunan tingkat kecemasan pada 
kelompok intervensi dapat terjadi karena adanya intervensi terapi musik. Terapi musik dapat membantu mengekspresikan perasaan dan memberi pengaruh positif terhadap kondisi suasana hati dan emosi seseorang. ${ }^{17}$ Terapi musik dapat memberikan efek yang menenangkan bagi responden, dapat mengurangi kegelisahan, membuat perasaan menjadi rileks, santai, serta dapat menstabilkan emosional. Hal-hal yang harus diperhatikan dalam pemberian terapi musik yaitu memilih jenis musik yang tidak terlalu cepat dan keras. ${ }^{18}$ Beat $60-80 /$ menit yang mempunyai nada yang teratur dan tetap, pasien memilih musik dengan arahan seorang terapis, maksimum volume $60 \mathrm{~dB}$, harmonisasi yang selaras ${ }^{18,19}$ serta didukung dengan ruangan yang nyaman, tenang, dan jauh dari kebisingan sehingga membuat seseorang dapat berkonsentrasi pada musik yang diberikan. ${ }^{7}$ Sesuai dengan keadaan di lapangan saat dilakukan penelitian bahwa pasien dihadapkan kepada situasi yang sama, yaitu akan menjalani operasi. Sehingga secara uji statistik ada perbedaan terhadap tingkat kecemasan pasien pre-test dan post-test pada kelompok kontrol dan kelompok intervensi.

Berdasarkan evaluasi dari pasien di Bangsal Bedah Ruang Melati RSUD Panembahan Senopati Bantul Yogyakarta setelah diberikan intervensi terapi music, respon responden sangat baik, dan tidak ada responden yang menolak untuk berpartisipasi dalam penelitian. Responden mengatakan bahwa mereka merasa rileks dan lebih tenang setelah mendengarkan terapi musik. Ada 2 responden perempuan yang menangis saat mendengarkan terapi musik. Mereka mengatakan emosi dapat terluapkan saat mendengarkan musik, sakit kepala menjadi hilang, dan tidak mual lagi. Satu responden setelah menjalani prosedur operasi ingin mendengarkan terapi musik lagi, responden tersebut mengatakan bahwa terapi musik dapat membuat dirinya rileks dan pikiran menjadi tenang.

\section{KESIMPULAN}

Berdasarkan hasil analisis data dan pembahasan maka kesimpulan dalam penelitian ini adalah terapi musik dapat menurunkan tingkat kecemasan pasien preoperasi.

\section{KEPUSTAKAAN}

1. Potter PA, Perry AG. Buku ajar fundamental keperawatan: konsep, proses dan praktik. Jakarta: EGC; 2006.

2. Muttaqin A, Sari K. Asuhan keperawatan perioperatif: konsep, proses, dan aplikasi. Jakarta: Salemba Medika; 2009.

3. Bolla NI. Gambaran tingkat kecemasan pada klien pra bedah mayor di ruang Rawat Inap Medikal Bedah Gedung D Lantai 3 Rumah Sakit Umum Cibabat Cimahi. Jurnal Kesehatan Kartika STIKES A Yani. 2008.

4. Faradisi F. Efektifitas terapi murotal dan terapi musik klasik terhadap penurunan tingkat kecemasan pasien preoperasi di 
Pekalongan. Jurnal IImiah Kesehatan. 2012;5(2).

5. Mau A, Kedang SB. Pengaruh terapi musik terhadap kecemasan pasien pre operasi di Ruang Anggrek, Cempaka, Dan Asoka Rsu. Prof. Dr. W. Z. Johannes Kupang. Jurnal kesehatan. 2013;1(1):1-6.

6. Sanjaya LR, Sulistyaningsih. Tapas Acupressure Technique (TAT) intervensi tepat untuk menurunkan kecemasan pada pasien preoperasi. Jurnal Media IImu Kesehatan. 2012;1(3):34-8.

7. Setyoadi, Kushariyadi. Terapi modalitas keperawatan pada klien psikogeriatrik. Jakarta: Salemba Medika; 2011.

8. Stuart GW, Laraia MT. Principles and practice of psychiatric nursing. 8th ed. St. Louis: Mosby; 2005.

9. Kahija YL. Hipnoterapi: prinsip-prinsip dasar pratik psikoterapi. Jakarta: Gramedia Pustaka utama; 2007.

10. Arslan S, Ozer N, Ozyurt F. Effect of music on preoperative anxiety in men undergoing urogenital surgery. Australian Journal of Advanced Nursing. 2007;26(2):46-54.

11. Qulsum A, Ismonah, Meikawati W. Perbedaan tingkat kecemasan pada pasien pre operasi sebelum dan sesudah pemberian terapi musik klasik di RSUD Tugurejo Semarang. Jurnal IImu Keperawatan dan Kebidanan. 2012;1(1).

12. Stuart GW. Buku saku keperawatan jiwa. 5th ed. Jakarta: EGC; 2007.

13. Jafar MF, Khan FA. Frequency of preoperative anxiety in Pakistani surgical patients. J Pak Med Assoc. 2009;59(6):359-63.

14. Trismiati. Perbedaan tingkat kecemasan pria dan wanita akseptor kontrasepsi mantap di RSUD Dr. Sardjito Yogyakarta. Jurnal PSYCHE. 2004;1(1).

15. Halgin R, Withbourne SK. Abnormal psychology clinical perspectives on psychological disorder Jakarta: Salemba Humanika; 2010.

16. Pawatte I, Pali C, Opod H. Perbedaan tingkat kecemasan pada ibu pre seksio caesarea di RSIA kasih ibu dan RSUP. Prof.Dr.R.D. Kandou Manado. Jurnal Kedokteran Komunitas dan Tropik. 2013;1(3):107-12.

17. Djohan. Terapi musik teori dan aplikasi Yogyakarta: Galang Press; 2006.

18. Elliott D, Pollman R, Mcgregor R. Relaxing music for anxiety control. J Music Ther. 2011;48(3):264-88.

19. Nilsson U. The anxiety-and pain-reducing effects of music interventions: a systematic review. AORN J. 2008;87(4):780-807. 